\title{
Aspectos da Gestão nos cursos superiores em Ciências Contábeis do Brasil: um estudo sobre a atuação dos Coordenadores
}

\author{
Aspects of Management in the higher courses of Accounting \\ Sciences of Brazil: a study about the performance of the \\ Coordinators
}

\section{Osmar Antonio Bonzanini ${ }^{1}$; Amélia Cristina Ferreira-da-Silva ${ }^{2}$; Teresa Gabriela Leite $^{3}$}

\author{
1 Universidade URI \\ Universidade Regional Integrada do \\ Alto Uruguai e das Missões \\ E-mail: bonzanini.prof@gmail.com \\ ${ }^{2}$ IPP \\ E-mail: ameliafs@gmail.com \\ ${ }^{3}$ Universidade Lusófona do Porto \\ E-mail: gabriela leite@sapo.pt
}

\begin{abstract}
Resumo
Este estudo teve como objetivo investigar como são geridos os cursos superiores destinados a diplomar os contadores no Brasil. A investigação é baseada na perceção dos coordenadores que, por norma, assumem atividades de docência e gerem os recursos humanos e materiais do curso. Trata-se de um estudo bibliográfico, exploratório e descritivo. Os resultados mostram que, contrariamente ao preconizado na atual Legislação Brasileira, os coordenadores não exercem a função com dedicação exclusiva. Sobre o tipo de decisão envolvida no processo de gestão dos cursos, o estudo revela que, em boa parte, os coordenadores não recebem quaisquer informações económico-financeiras para sustentar o processo decisório do curso ao seu encargo.
\end{abstract}

Palavras-chave: Gestão, Coordenador, Cursos Superiores, Universidades.

\begin{abstract}
This paper aimed to investigate how the graduation courses in accounting are being managed in Brazilian universities. The research is based on the perception of their courses' coordinators who assume teaching activities and manage the human and materials resources of the course. It is a bibliographic, exploratory and descriptive study. The results show that, contrary to what is recommended in the current Brazilian Law, the coordinators do not perform their job functions with exclusive dedication. Regarding the type of decision involved in the course management process, the study reveals that, to a large extent, coordinators do not receive any economic or financial information to support the course decision-making process.
\end{abstract}

Keywords: Management, Coordinator, Higher Education, Universities. 


\section{Introdução}

Ao longo das últimas décadas, a expansão do número de cursos de ensino superior tem sido crescente, por conta dos conhecimentos e habilidades que envolvem a qualificação dos académicos, enquanto futuros profissionais. Nesse contexto, as instituições de ensino superior (IES), representadas por universidades, faculdades, centros universitários e institutos educacionais, fornecem conhecimentos e certificam as competências técnicas dos profissionais, além de sustentarem a sua capacidade de resolução dos problemas dos seus clientes (Muzio, Kirkpatrick \& Kipping, 2011; Rodrigues, 2012).

Consideradas como organizações diferenciadas, tendo em conta que atuam na educação, pesquisa e atividades de extensão na sociedade, em termos administrativos, as IES tornaramse complexas e precisam encontrar novas formas de financiamento, além de competir por bolsas de pesquisa com outras universidades (Scharrock, 2012). Adicionalmente, os efeitos das últimas crises financeiras também causaram impacto no orçamento de IES públicas e privadas, resultando na busca de novas estratégias institucionais para a sua sustentabilidade. Assim, a necessidade de existir um corpo administrativo, com liderança e capacidade para atuar frente à gestão de uma organização, tem sido citada desde a década de 1970, a partir do pioneirismo de Fayol.

Também é preciso observar, de início, que o ambiente e a dinâmica da educação superior sofreram interferências legais, primeiramente por parte do Ministério da Educação (MEC), além de influências políticas, económicas e financeiras, contribuindo para aumentar as exigências em relação ao papel e à atuação do gestor dos cursos superiores (Bonzanini, 2012; Carvalho, 2014). Desta forma, a atividade de coordenar é, certamente, uma das áreas-chave de uma instituição de ensino, sendo que, nas IES brasileiras, as atribuições formais dos coordenadores estão previstas em regimentos gerais, aprovados pelos seus conselhos superiores, em complemento à legislação do MEC. Tal ocorre em todos os cursos, inclusive naqueles destinados a formar contadores, dos quais possuem prerrogativas de profissão regulamentada para atuar no Brasil.

No meio educacional, conforme Tanaka e Pessoni (2011), não há discordância de que a coordenação de curso apresenta-se como uma função de grande relevância para a efetivação de um ensino superior de qualidade, isto porque essa tarefa não é apenas administrativa, no sentido usual, mas também uma busca de eficiência dos meios de trabalho com características de quem atua como gestor.

De acordo com a atual legislação brasileira, os coordenadores de cursos superiores têm ao seu encargo toda a análise da qualidade académico-institucional dos serviços oferecidos à comunidade e a relação económica da estrutura do curso e sua consequente margem de contribuição para o sucesso do serviço de oferta (Marcon, 2011). Os coordenadores atuam na organização e gestão dos recursos materiais do espaço físico e das instalações de uso geral e específico, destinados ao ensino de graduação. São docentes que assumem o cargo de coordenador por conta da indicação de um conselho da reitoria ou por eleição entre seus pares.

$\mathrm{Na}$ fase em que ocorre a mudança da sua condição de professor para coordenador, o eleito inicia as atividades sob a responsabilidade da função gerencial, a par da sua função de docente. Acresce, deste modo, a possibilidade de existir conflitos com colegas e superiores, derivados de uma formação técnica específica, aliada à escassez de recursos que tende a repercutir na gestão da instituição, inclusive nas coordenações de curso, criando uma dinâmica própria. Todo este panorama permite visualizar um campo profícuo para a realização deste estudo, visto que ao assumirem um papel central na gestão dos cursos e por sua posição, onde se cruzam visões, interesses e pressões de vários quadrantes, os coordenadores tornamse numa fonte de informação excepcionalmente rica.

Diante de tal quadro, a questão inicial deste estudo é: como a gestão nos cursos superiores em Ciências Contábeis no Brasil é exercida atualmente? Não podendo deixar de referir que a investigação teve como foco a atuação de todos os coordenadores dos cursos superiores em

E3 - Revista de Economia, Empresas e Empreendedores na CPLP | Volume 3 | Número 1 
Ciências Contábeis ofertados no Brasil. A partir da introdução, o texto está dividido em quatro secções, a saber: contexto e revisão de literatura, procedimentos metodológicos, apresentação e discussão dos resultados e as conclusões, limitações e perspectivas de novos estudos.

\section{Contexto e revisão de literatura}

No Brasil, as atribuições dos coordenadores de cursos superiores estão formalmente previstas na legislação do Ministério da Educação (MEC) - que estabelece vínculos e visa interligar a atual Lei das Diretrizes e Bases da Educação e a Lei do SINAES - Sistema Nacional de Avaliação do Ensino Superior (MEC, 2010). No Instrumento de Avaliação dos Cursos de Graduação, o MEC instituiu os indicadores para o coordenador de curso, os quais são avaliados nos seguintes itens: titulação e área de graduação (pertinência com a área do curso), participação nos órgãos colegiados académicos da IES; experiência profissional académica; experiência profissional não-académica (mas relacionada com o curso); possuir um regime de trabalho, a tempo parcial ou integral, na IES, relacionado com o número de vagas do curso que coordena.

Estudos anteriores realizados no Brasil, onde os coordenadores dos cursos superiores em Ciências Contábeis figuram como tema principal de investigação, estão voltados ao perfil, formação e atuação destes, bem como aos conteúdos programáticos e curriculares. Entre eles, destacam-se aqueles realizados por Grunow, Sabadin, Fassina, e Domingues (2006), Domingues, Peleias, Walter e Kroenke (2011), Santos, Domingues e Ribeiro (2013), Marcon (2011), Carvalho (2014), Ferrari e Nascimento (2014) e, Walter, Schneider, Rocha, Domingues e Tontini, (2012). No entanto, tais estudos foram realizados com amostra reduzida, como de um único Estado ou região do país (Grunow et al., (2006) ou, ainda, em uma única IES (Marcon, 2011; Ferrari e Nascimento, 2014).

Por outro lado, os coordenadores de curso atuam em um ambiente onde permeiam, ao mesmo tempo, os conceitos e aplicações relacionados com as informações geradas pela contabilidade, ou seja, insumos utilizados na gestão, além das questões políticas muito próprias da universidade, cujas nuances desse ambiente envolvem ensino, pesquisa e extensão, resultando em interação com a sociedade. Portanto, trata-se de uma atividade com diversas características e atribuições.

\section{Características e competências do coordenador no ensino superior}

O papel de um coordenador de ensino superior envolve uma série de atribuições, as quais aumentam ou diminuem de acordo com a IES que atua. No caso de instituições públicas, além das atribuições propriamente ditas, há um viés mais voltado à pesquisa e às atividades académicas (MEC, 2010). Nas IES particulares e comunitárias, emerge um papel com características muito próprias da gestão, inclusive na obtenção de resultados que devem contribuir para a sustentabilidade da própria IES.

A primeira atribuição do coordenador está relacionada com o conhecimento de legislação, contemplando o domínio dos instrumentos de regulação. Além disso, devem ter compromisso institucional, já que o Projeto Pedagógico do Curso deixará de ser uma peça isolada nas IES. Portanto, deve saber-se se a missão institucional está expressa nos processos académicos, promovendo a implantação da proposta do curso, objetivando a qualidade e aprovação nos exames da Ordem Profissional.

Visando contribuir para a gestão dos cursos de graduação em suas afiliadas, a ABMES Associação Brasileira de Mantenedoras de Ensino Superior ${ }^{1}$ - identifica quatro requisitos que despontam como básicos para o exercício das funções de coordenador de curso. O primeiro propõe que o professor indicado tenha titulação de mestre ou doutor (ABMES, 2011). Assim, independentemente de sua função gerencial, a titulação necessária e definida pelo MEC (2010)

\footnotetext{
${ }^{1}$ Associação privada, criada com o objetivo de representar a categoria a nível nacional e lutar pelos interesses legítimos das instituições particulares de ensino superior.

E3 - Revista de Economia, Empresas e Empreendedores na CPLP | Volume 3 | Número 1
} 
mostra-se fundamental para que o coordenador possa comandar seus docentes com similar titulação. A ideia predominante é de que um coordenador de curso, detentor tão somente de graduação ou especialização, encontrará dificuldades para comandar mestres e doutores. $O$ segundo requisito, preconizado pela ABMES (2011), indica que o coordenador deve atuar pelo regime mensal de 44 horas semanais, o que permite maior dedicação ao desenvolvimento do curso em todas as suas dinâmicas.

Quanto ao terceiro requisito, a ABMES (2011) entende que o indicado deve ministrar aulas para, ao menos, duas turmas do curso que coordena, a fim de manter o contacto académico com os alunos e proporcionar o melhor exemplo aos seus colegas. Em relação ao quarto requisito, a ABMES enfatiza que o coordenador deve ter eficaz competência gerencial para administrar o curso. Portanto, os requisitos apontados pela ABMES - a titulação, o comando, a dedicação ao curso e o espírito gerencial, enquanto qualificação diretiva - são aspectos que deveriam balizar a qualificação para ao cargo seja ele identificado como coordenador, gestor ou diretor de curso.

Com base na atual legislação brasileira, os coordenadores de curso têm ao seu encargo toda a análise da qualidade académico-institucional dos serviços oferecidos à comunidade e da relação económica da estrutura do curso e sua consequente margem de contribuição para 0 sucesso do serviço ofertado (Bonzanini, 2012; Marcon, 2011). Assim, os coordenadores atuam na organização e gestão dos recursos materiais, do espaço físico e das instalações de uso geral e específico, destinados ao ensino de graduação.

Coordenações de curso, de acordo com Walter et al. (2012), consistem num colegiado que tem a responsabilidade de conduzir os assuntos diretamente relacionados ao ensino de graduação. O seu surgimento decorre das inovações da Reforma Universitária de 1968, em substituição aos Conselhos Técnicos e Administrativos e Congregações e na adequação às questões legais, do qual as IES denominam de coordenação de curso. Adicionalmente, as exigências sobre os coordenadores dos cursos de graduação envolvem atribuições e atuações no sentido de manter a IES competitiva, diante das pressões ambientais internas e externas (Domingues et al., 2011), o que significa, no âmbito da gestão, os cuidados com pontos fortes e fracos, bem como das questões voltadas aos resultados e competências gerenciais, enquanto capacidade em mobilizar, integrar e bem aplicar recursos.

Uma vez conduzido ao cargo, o coordenador é motivado a assumir uma postura de gestor, algo que não pode ser visto de forma simples, tendo em vista que boa parte desses profissionais, no momento da posse no cargo, não possui uma bagagem de conhecimentos essenciais sobre a legislação educacional, noções de marketing, gestão de pessoas e similares, bem presentes nas atividades de coordenador de curso (Bonzanini, 2012; Carvalho, 2014).

Quanto às atividades que desenvolve, a percepção inicial é de que os Coordenadores de cursos de graduação atuam no trabalho em equipa e na elaboração de projetos, cujas ações devem estar alinhadas com os objetivos estratégicos previstos no âmbito da instituição (Borrel\& León, 2010; Marcon, 2011). Mesmo com tais atribuições, a comunidade académica espera que ele apresente comportamentos característicos de um gerente, ainda que continue sendo professor, mas com nova identidade profissional.

Sobre a particularidade em ser um gestor, Ferrari e Nascimento (2014) enfatizam que, para atuar como tal, o coordenador de curso superior deve alcançar resultados que podem envolver, entre outros pontos, um conceito positivo nas avaliações a que o curso é submetido. Assim, deverá manter os baixos índices de evasão no curso que coordena, além do elevado nível de relacionamento com os professores, alunos e demais gestores da IES onde atua.

Palmeiras e Szilagyi (2011) afirmam que ainda não foi possível chegar a um denominador comum quanto às funções, atribuições e encargos do coordenador de curso. O que predomina é a figura de um coordenador que possui responsabilidades gerenciais, políticas e institucionais, em sentido restrito dessas atribuições, à frente de um colegiado composto por professores com diferentes titulações.

Nesse contexto, cabe ao gestor do curso exercer uma função de articulação entre os corpos docente e discente, na consecução do processo de ensino-aprendizagem (Chinchila \& Cruz, E3 - Revista de Economia, Empresas e Empreendedores na CPLP | Volume 3 | Número 1 
2011). Também, compete ao Coordenador viabilizar as ações de interação entre académicos, conhecimentos e professores, tendo como apoio as reuniões que priorizam as discussões pedagógicas e as reflexões coletivas.

Por outro lado, o preparo mínimo do Coordenador de curso é imprescindível para uma melhor condução da gestão, atuando na capacitação individual e visando a compreensão dos processos de planeamento, intervenção e resistência às mudanças (Palmeiras \& Szilagyi, 2011; Carvalho, 2014). Adicionalmente, o setor de recursos humanos das IES necessita ser estruturado de acordo com os objetivos e relacionado com o seu cargo mais estratégico, o de professor. Portanto, não bastam planos de carreiras e de gestão, mas também será necessário o desenvolvimento de planos que qualifiquem o professor que atua dentro e fora da sala de aula.

O desempenho satisfatório do coordenador de curso superior, de acordo com Ferrari e Nascimento (2014), pode ser considerado essencial na efetivação de um curso de ensino de qualidade, por conta do papel do seu gestor, visto que assume, além das funções académicas e científicas, outras funções ligadas às questões administrativas. Contudo, conforme as mesmas autoras, a profissionalização dos Coordenadores é algo muito recente no setor da educação, assim como a imagem da IES, vista como uma empresa.

Visando ilustrar a escala avaliativa do MEC, os menores indicadores serão atribuídos quando 0 coordenador não possuir qualquer tipo de graduação na área do curso, não tiver uma titulação, obtida em programas de pós-graduação stricto sensu, ou experiência de magistério superior de, no mínimo, dois anos. Quanto ao regime de trabalho na IES, a menor pontuação também é atribuída ao coordenador que não possuir tempo parcial ou integral. Já a maior pontuação destina-se ao coordenador com tempo parcial ou integral, considerando o somatório das vagas anuais do curso e respeitado o patamar mínimo de dez horas semanais (MEC, 2010). Portanto, a titulação, ser mestre ou doutor, e a experiência de magistério superior, além das horas dedicadas à coordenação, são essenciais na avaliação do curso.

Tendo em conta o ambiente de atuação e as exigências que pesam sobre o trabalho do coordenador, Carvalho (2014) aponta três aspectos fundamentais no processo de coordenar um curso superior: a liderança, o conhecimento e a capacidade de pensar e agir estrategicamente. Estes aspectos são capazes de promover as mudanças necessárias para 0 melhor desenvolvimento das potencialidades no interior dos cursos e, embora não haja consenso sobre as ações mais desenvolvidas pelos Coordenadores, estão voltadas às atividades internas, ponto que, na visão de Almeida-Santos, Domingues, Melo, e Cunha (2013), deve ser objeto de reflexão, visto que as ações consideradas como mais importantes à função nem sempre são realizadas.

Assim, existem discrepâncias entre ações desejadas e efetivamente realizadas, além da necessidade de maior clareza entre os superiores e os gestores, visando o alinhamento do desempenho dos gestores. Deste modo, tendo como referência a legislação imposta pelo MEC, as IES têm incluído, em seus regimentos internos, as atribuições dos Coordenadores de curso, as quais estão, quase sempre, elencadas de forma genérica, sem indicação específica a um ou outro curso.

O conjunto de requisitos apontados pela ABMES (2011) e MEC (2010), ou seja, a titulação, o comando, a dedicação ao curso e o espírito gerencial, enquanto qualificação diretiva, deveriam balizar a contratação ou qualificação para o concurso ao cargo de um dirigente de curso, sendo ele identificado como coordenador ou diretor de curso.

Portanto, de maneira geral e independentemente dos termos utilizados, a gestão dos cursos superiores no Brasil deve conduzir a ótimos resultados educacionais e financeiros. No contexto das instituições privadas, o coordenador deverá atuar de forma a atrair novos alunos, mantendo os baixos índices de desistência, para além de garantir o bom relacionamento entre os docentes que se encontram sob a sua coordenação. 


\section{Atuação e atribuição dos Coordenadores de Ciências Contábeis}

Atuando à frente de um curso superior que titula o profissional com o título de contador, nem todos os Coordenadores de curso têm a responsabilidade de atuar em todas as áreas, como a gestão financeira, por exemplo, onde as receitas e despesas vinculadas ao curso podem estar incluídas no orçamento global da IES.

Carvalho (2014) referencia a própria experiência profissional, destacando algumas problemáticas que emergem da falta de definição clara das atribuições do coordenador, como no caso em que este assume o papel de executor das decisões e do próprio planeamento definido por Direções de Campus e/ou Reitoria. Igualmente, ao receber atribuições burocráticas e administrativas, tais como alimentar sistemas operacionais, resolver problemas com alunos e professores faltosos, que podem, quase sempre, ser desenvolvidas por profissionais de apoio, a exemplo do que ocorre na gestão das empresas em geral.

Observa-se que o coordenador de Ciências Contábeis precisa atuar em conjunto com os docentes do curso, devendo possuir determinadas competências, as quais estão classificadas nas etapas do processo de gestão como planeamento, execução e controlo (Domingues et al. 2011; Alencar \& Araújo, 2011). Assim, o coordenador deve possuir a visão de todo o curso, inclusive do corpo docente, sobre o qual tende a exercer influências. Ainda, por tratar-se de uma profissão legalmente regulamentada, no Brasil, o coordenador de curso de Ciências Contábeis necessita atuar em estreita ligação com os Conselhos de Contabilidade.

De acordo com Grunow et al. (2006), os Coordenadores de curso de Ciências Contábeis, no contexto das IES, devem ter presente a preocupação quanto ao desempenho e à qualidade da sua gestão, mediante a utilização de um conjunto de atividades inerentes. Essas atividades devem contemplar o incentivo à organização de uma estrutura de ensino crítico, que possibilite ampliar as fontes de informação sobre o ambiente social, o estímulo à consecução do projeto pedagógico de maneira clara, objetiva e democrática, em que as experiências do saber empírico sobre as Ciências Contábeis sejam consideradas como reserva estratégica para a construção do saber científico sobre o saber real, entre outros.

Para o exercício do cargo de coordenador de curso de Ciências Contábeis nas IES brasileiras, as exigências legais são as mesmas dos demais cursos de graduação, fundamentadas em três requisitos: ter titulação de mestre ou doutor, conforme exigências do MEC; atuar pelo regime mensal de 40 horas semanais, com dedicação e ministrando aulas do curso (Walter et al., 2012). Embora o entendimento de Grunow et al. (2006), em que a coordenação do curso de Ciências Contábeis é, preferencialmente, exercida por um contador, tal não pode ser tomado como definitivo, devido às questões ligadas ao exercício profissional. Ocorre que, ao atuar como coordenador e docente exerce-se uma atividade profissional, devendo seguir o código da categoria, o que remete à necessidade de ser graduado em Ciências Contábeis e com registo no CRC.

Do estudo realizado por Grunow et al. (2006), considerando a análise do perfil dos Coordenadores de Ciências Contábeis, resultou um conjunto de atribuições e competências inerentes à função, conforme consta no seguinte quadro:

\section{Quadro 01 - Atribuições e competências do Coordenador de Ciências Contábeis}

I) Coordenar as atividades de ensino, pesquisa e extensão do curso e organizar o currículo pleno do mesmo, ouvido o corpo docente;

II) Aprovar, no âmbito da sua competência, planos e programas de ensino e alterações curriculares, de forma a propor medidas para o aperfeiçoamento do ensino e condições para pesquisa e extensão;

III) Orientar, coordenar os trabalhos de conclusão de curso, exigidos pela lei, e elaborar um horário de aulas e das demais atividades didáticas do curso;

IV) Supervisionar a integralização curricular e orientar alunos, de modo a poder deliberar sobre os recursos ou representações de alunos a respeito de matéria didática e trabalhos escolares;

E3 - Revista de Economia, Empresas e Empreendedores na CPLP | Volume 3 | Número 1 
V) Verificar a execução do sistema de avaliação do corpo discente e docente e dar parecer na indicação e dispensa do docente;

VI) Convocar e presidir as reuniões do corpo docente do curso, coordenando os trabalhos dos membros do mesmo corpo docente;

VII) Acompanhar a assiduidade dos docentes e profissionais técnico-administrativos vinculados ao curso e fiscalizar a observância do regime escolar e do cumprimento dos planos de ensino, tendo em consideração os demais planos de trabalho;

VIII) Avaliar o desempenho docente, discente e técnico-administrativo, segundo propostas dos colegiados superiores;

IX) Estabelecer, observadas as normas baixadas pelas Instituições de Ensino Superior, para aproveitamento de estudos, adaptações, dependências e avaliação da aprendizagem, e deliberar sobre pedidos de transferências;

$\mathbf{X ) ~ A p r e s e n t a r ~ p r o p o s t a s ~ p a r a ~ a ~ a q u i s i c ̧ a ̃ o ~ d e ~ m a t e r i a l ~ b i b l i o g r a ́ f i c o ~ e ~ d e ~ o u t r o s ~ e q u i p a m e n t o s ~}$ necessários para o bom desempenho do ensino, pesquisa e extensão do curso;

XI) Deliberar sobre a organização e administração de laboratórios e outros materiais didáticos, quando esses constituírem parte integrante do ensino e da pesquisa;

XII) Apresentar à reitoria, no prazo estabelecido, relatórios das atividades do curso e propor a admissão de monitor, quando necessário;

XIII) Zelar pela regularidade e qualidade do ensino ministrado pelo curso e avaliar periodicamente $o$ andamento e os resultados dos projetos de pesquisa e dos planos de extensão sob a sua responsabilidade;

Fonte: adaptado de Grunow et al. (2006).

É necessário ressaltar que a proposição de Grunow et al. (2006) não é definitiva e se assemelha, em boa parte, às atribuições referidas pela ABMES (2011), Walter et al. (2012) e Almeida-Santos et al. (2013). Desta forma, as principais ações executadas pelos coordenadores de Ciências Contábeis derivam para a atuação voltada ao mercado profissional; pesquisa e extensão; próxima aos académicos e professores; atividades de planeamento político e pedagógico; capacitação de docentes e em reuniões de colegiado e departamento.

Pela ordem, a atenção aos alunos, professores, reuniões e atividades político-pedagógicas são aquelas que mais absorvem o tempo do gestor. A maioria dos gestores são homens, graduados em Ciências Contábeis, e o seu vínculo principal é na IES, na gestão do curso que coordenam (Domingues et al., 2011; Almeida-Santos et al., 2013). Mesmo com tal vínculo, um número considerável dos coordenadores atua como docente em outras IES.

\section{Coordenadores como gestores}

O papel de um coordenador de ensino superior contempla uma série de atribuições, as quais aumentam ou diminuem de acordo com a IES em que atua. No caso de instituições públicas, além das atribuições propriamente ditas, há um viés mais voltado à pesquisa e às atividades académicas. Nas IES particulares e comunitárias, emerge um papel com características muito próprias da gestão, inclusive na obtenção de resultados que devem contribuir para a sustentabilidade da própria IES.

A partir dos estudos já referidos neste texto, em que o coordenador de ensino superior é o principal sujeito de investigação, observa-se, muito mais, a figura de quem precisa atuar como gestor de uma equipa, dando conta de incontáveis atribuições. No entanto, o coordenador continuará sendo docente no próprio curso e em outros cursos da IES. Adicionalmente, no estudo realizado por Grunow et. al., (2006), além de atribuições que envolvem ensino, pesquisa e extensão, o coordenador deve atuar para organizar e fazer cumprir o currículo pleno do curso, em conjunto com o corpo docente.

Com base na abordagem de diversos autores, entre os quais Grunow et al. (2006); Marcon (2011); Almeida-Santos et al. (2013); Domingues et al. (2011) e Walter et al. (2012), infere-se

E3 - Revista de Economia, Empresas e Empreendedores na CPLP | Volume 3 | Número 1 
que, em boa parte, as atribuições dos coordenadores dos cursos de graduação, nas IES brasileiras, são semelhantes. Contudo, o ponto que tem provocado dúvidas não está naquilo que é explícito ou definitivo, mas sim diante da existência de termos como 'atribuições compatíveis com a função' e 'atividades inerentes ao cargo', no conjunto das atribuições, o que permite generalizações na direção de um sujeito que executa múltiplas tarefas. A multiplicidade de tarefas, que Gaglio (2013) identifica como malabarismo, não deve ser vista como heroica, pois remete ao perfil de quem atua de forma isolada, lutando para manter a organização em funcionamento.

Por outro lado, além das atribuições regimentais, como aquelas elencadas no Quadro 01, estas envolvem outras tarefas, como citado pela ABMES (2011), num conjunto de ações que pendem para uma atuação direcionada ao mercado profissional e bastante próxima aos académicos, concomitante às atividades de planeamento político e pedagógico, para além de planear e conduzir reuniões com todo o corpo docente.

Mesmo com toda essa carga de atividades, em IES não públicas, os resultados económicos do curso coordenado devem ser positivos, visando a questão da própria sustentabilidade da organização. Ao passo que nas IES públicas os recursos previstos no orçamento nem sempre são disponibilizados, o que tende a trazer problemas aos Coordenadores.

\section{Procedimentos Metodológicos}

Este estudo, no contexto das ciências sociais, classifica-se como sendo de natureza exploratória e descritiva, qualitativo e bibliográfico, de acordo com os conceitos apresentados por Berg e Lune (2014), Bhattacherjee (2012), Sousa e Baptista (2011) e Beuren (2013). Para a recolha dos dados, utilizou-se o questionário, instrumento constituído por uma série de perguntas, as quais devem ser respondidas por escrito pelo informante, sem a presença do pesquisador (Beuren, 2013), mediante o uso, por exemplo, de questões fechadas, no formato da escala de Likert (1932).

Os participantes deste estudo, os 980 Coordenadores de Ciências Contábeis do Brasil, identificados a partir de um relatório fornecido pelo Conselho Federal de Contabilidade (CFC), em janeiro de 2014. A amostra é constituída por 436 respostas, obtidas nos questionários enviados por meio eletrónico, através da ferramenta Google Docs. Para confirmar a sua validade, utilizou-se a fórmula proposta por Triola (2013), como cálculo do erro de proporções em populações finitas ${ }^{2}$. O inquérito foi concluído em outubro de 2014 , iniciando-se, então, a sistematização dos dados.

Visando conhecer a atuação dos Coordenadores dos Cursos Superiores em Ciências Contábeis e fomentando questão de partida, estes foram inquiridos num conjunto de questões, conforme consta no Quadro 02, a seguir.

Quadro 02 - Conjunto de questões encaminhadas aos Coordenadores de Ciências Contábeis

Q1) Titulação (Graduado, especialista, mestre, doutor, pós-doutor)

Q2) Género (masculino, feminino, outro)

Q3) Tempo de atuação no ensino superior (em anos)

Q4) Tempo de atuação como coordenador (em anos)

Q5) Idade (em anos)

Q6) Há quanto tempo (em anos) possui registro profissional no respectivo Conselho Regional de Contabilidade?

Q7) Além de coordenador de curso, atua profissionalmente em atividades externas à IES?

Q8) Levando em conta a sua atuação, nos limites da IES onde coordena o curso, quais outras atribuições desempenha, além da atividade de coordenador?

\footnotetext{
${ }^{2}$ Amostra superior a $5 \%$, o que permite afirmar, com $95 \%$ de confiabilidade, que as proporções encontradas neste estudo possuem uma margem de erro máxima de 3,5\%.

E3 - Revista de Economia, Empresas e Empreendedores na CPLP | Volume 3 | Número 1
} 
Q9) Quanto aos docentes que atuam no curso que coordena, possui autonomia para contratar, manter, substituir ou demitir?

Q10) Recebe informações económicas e/ou financeiras (a partir das instâncias superiores), visando a melhor gestão do curso que coordena?

Q10.1) Em caso afirmativo:

a) Em relação às finalidades (são suficientes, não são suficientes, são parcialmente suficientes);

b) Em relação à periodicidade e tempestividade (atendem totalmente, não atendem, atendem parcialmente tais aspectos);

c) Sobre a utilização dessas informações nas decisões na gestão do curso (utiliza regularmente, utiliza periodicamente, não utiliza, utiliza eventualmente).

Fonte: dados do estudo.

\section{Apresentação e discussão dos resultados}

A seguir, estão evidenciados os resultados obtidos no inquérito realizado, cuja amostra compreendeu 436 Coordenadores de Curso de Ciências Contábeis, em atuação no Brasil, a partir da sistematização das respostas obtidas no inquérito enviado. Os Coordenadores em atuação no país possuem, na sua maioria, o título de Mestre, seguido de Especialistas, enquanto que os Doutores estão em minoria, conforme o Gráfico 01, a seguir.

Gráfico 01 - Titulação dos Coordenadores de Ciências Contábeis

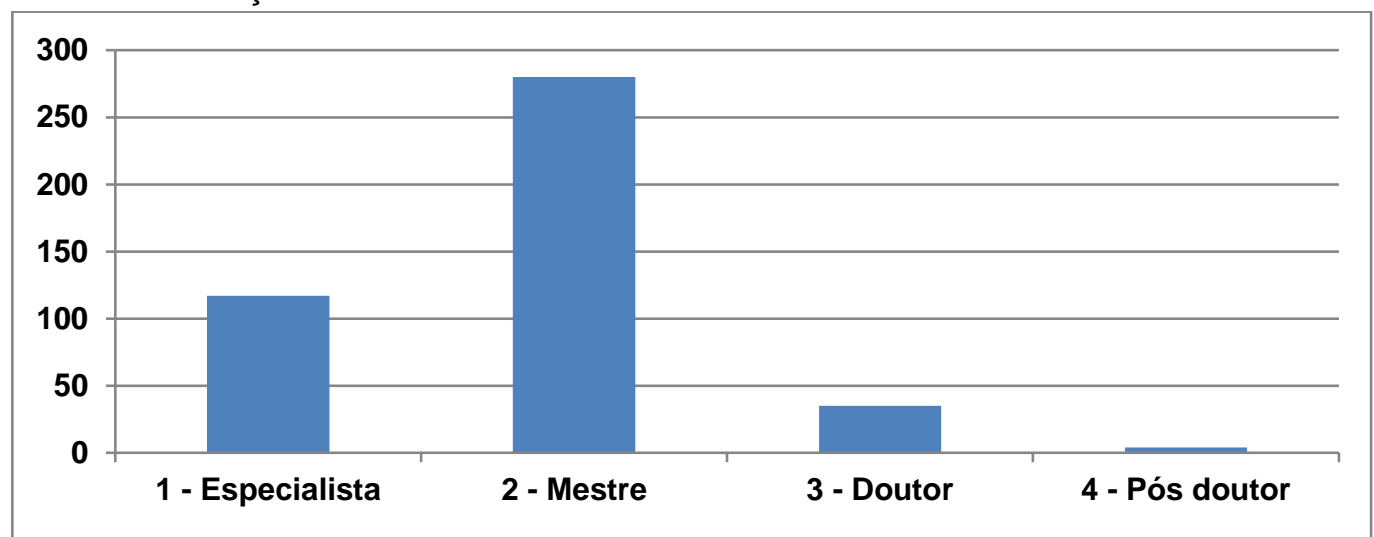

Fonte: dados do estudo.

Quanto ao género, mais de $67 \%$ são homens (293) e, no requisito de idade, o coordenador mais jovem tem 23 anos e a idade mais avançada corresponde a 74 anos, com média de 45 anos. A faixa etária com maior número de respondentes está compreendida entre os 40 e os 50 anos.

Ao serem inquiridos sobre o tempo de atividade como docentes no ensino superior (Q3), as respostas demonstram alternância entre menos de 1 e 40 anos de atuação, para uma média de 13 anos. Verifica-se que pouco mais de $18 \%$ dos Coordenadores em atividade possuem tempo igual ou inferior a 5 anos no ensino superior e, com tempo igual ou superior a 30 anos na docência, foram 18 casos, o que representa pouco mais de $4 \%$.

Relativamente ao tempo em atividade na função de Coordenador de curso (Q4), o período variou de menos de 1 , até 29 anos na função, com média de 5 anos. No requisito de idade (Q5), a mínima é de 23 e a máxima de 74 anos, com média de 45 anos. A diferença entre 0 Coordenador com idade superior e o mais jovem é de 51 anos e a faixa etária com maior número de respondentes está nos 40 e nos 50 anos.

Inquiridos sobre o tempo de registro profissional como contador junto ao respectivo Conselho Regional de Contabilidade (Q6), visto tratar-se de uma profissão regulamentada, a média ficou 
na casa dos 16 anos. Nesse questionamento, observa-se que $11 \%$ dos Coordenadores não possuem esse registro e o maior tempo está em 48 anos.

$\mathrm{Na}$ sequência, os respondentes foram questionados sobre a atuação profissional em atividades externas à IES (Q7), somente $36 \%$ da amostra informaram atuar com dedicação exclusiva nas atividades como coordenador. Os demais, o que equivale a $64 \%$, exercem atividades profissionais externas à IES onde atuam.

Levando em consideração os limites da IES onde atua como Coordenador (Q8), foi perguntado aos respondentes quais outras atribuições desempenhavam, além das atividades específicas de coordenador. Nesta questão, o percentual de Coordenadores que não realizam nenhuma atividade adicional não chega a $2 \%$. Consoante o Gráfico 02, essas atividades envolvem a docência (no próprio curso e em outros cursos) e a divulgação das vagas em períodos de ingresso na orientação de estágio e até na cobrança de inadimplentes.

Gráfico 02 - Desempenho de atividades adicionais à função de coordenar

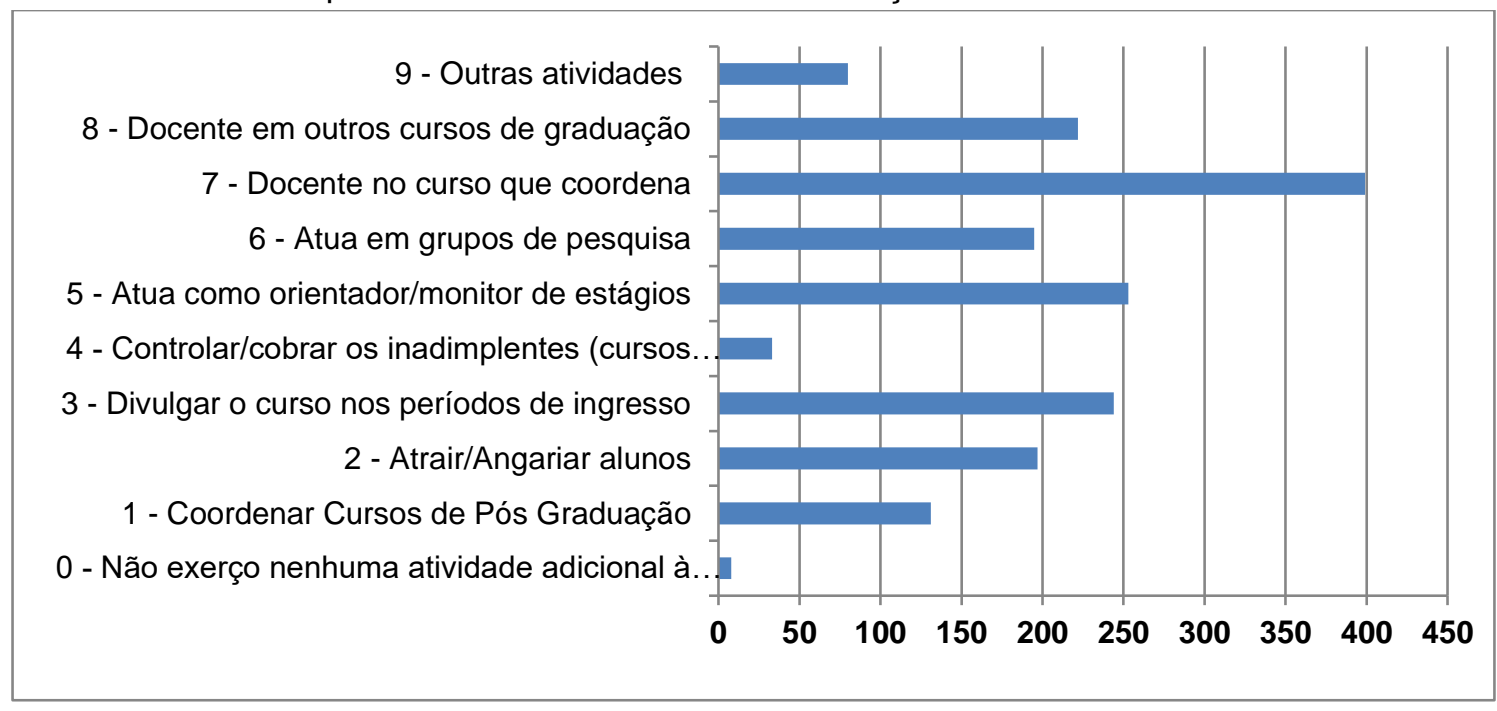

Fonte: dados do estudo.

Na questão seguinte (Q9), os Coordenadores informaram sobre a atuação em relação aos docentes que estão sob a sua responsabilidade, quanto à autonomia para contratar, manter, substituir ou demitir. Nas respostas, $32 \%$ informaram possuir total autonomia para isso, ao passo que pouco mais de $9 \%$ não possui nenhuma dessas atribuições. Os demais possuem autonomia limitada, podendo apresentar sugestões às instâncias superiores.

O último questionamento $(\mathbf{Q 1 0})$ foi colocado nos seguintes termos: recebe informações económicas e/ou financeiras (a partir das instâncias superiores), visando a melhor gestão do curso que coordena? Nas respostas, 231 Coordenadores responderam positivamente, enquanto que os demais (205) afirmaram não receber tais informações, o que corresponde a $47 \%$ da amostra.

Aos Coordenadores que afirmaram receber informações para a gestão do curso, foram acrescentados outras três questões. Na primeira, 58\% concordou que as informações são suficientes para as finalidades a que se destinam, enquanto que $7 \%$ afirma serem insuficientes. Os demais, $35 \%$, entendem que são parcialmente suficientes. No segundo questionamento (periodicidade e tempestividade), $48 \%$ dos coordenadores concordam que atendem tais aspectos, frente a $43 \%$ (atendem parcialmente) e para os demais $9 \%$ que não atendem.

No terceiro questionamento da Q10, os Coordenadores responderam sobre a utilização das informações recebidas nas decisões que envolvem a gestão do curso, sendo que $3 \%$ não faz uso das mesmas, frente a $48 \%$ que as utiliza regularmente. Ainda, $25 \%$ dos Coordenadores utilizam periodicamente tais informações e os demais, $24 \%$, fazem uso eventual das mesmas. 


\section{Conclusões, limitações e perspectivas de novos estudos}

Face às respostas obtidas, infere-se que os Coordenadores de Ciências Contábeis em atuação no Brasil são, em maioria, do género masculino e possuem a titulação de mestre, seguido dos especialistas. Em média, os Coordenadores de Ciências Contábeis no Brasil possuem 5 anos de atuação, havendo casos com tempo superior a 29 anos. Conclui-se que o maior número apresentado corresponde aos Coordenadores que possuem menos de 5 anos na função.

Mesmo diante da evidência de que a maioria dos Coordenadores detém o Título de Mestre, há que observar o elevado número de Especialistas que coordenam cursos, aspecto que, na avaliação do MEC (2010), resulta na menor pontuação. Para além do mais, no entendimento da ABMES (2011), os Especialistas tendem a encontrar dificuldades na função, visto que estariam a comandar Mestres e Doutores. Outro factor que pode resultar em prejuízo à avaliação do curso está no regime de trabalho exercido pelo Coordenador junto à IES. Neste estudo, as evidências demonstram que a maioria dos Coordenadores possui outra atividade profissional, ou seja, embora atendam requisitos como carga horária na IES, esta não é a única atividade exercida, conforme evidenciado no estudo de Almeida-Santos et al. (2013).

$\mathrm{Na}$ avaliação dos cursos, o MEC (2010) também observa o tempo de experiência no magistério superior, considerando, como nota máxima, a atuação igual ou superior a 5 anos e, como pior indicador, o tempo inferior a 2 anos. Embora a evidência de Coordenadores com tempo superior a 30 anos na docência, em 18\% dos casos, estes possuem menos de 5 anos de atuação no ensino superior.

Um aspecto a ser analisado, em especial, está relacionado ao Registo Profissional. Constatase, a partir das respostas obtidas, a atuação de Coordenadores que não possuem Registo Profissional como contador, junto à respectiva Ordem. Trata-se de uma incoerência, visto que atuam à frente de um curso que diploma futuros profissionais, os quais necessitam de registo para o exercício legal da profissão.

A atividade de coordenar um curso, sem outras atribuições adicionais, é um privilégio de poucos Coordenadores de Ciências Contábeis. Os restantes, além da atuação como docente no próprio curso e em outros cursos da mesma IES, exercem outras atividades, como a divulgação externa do curso, a coordenação de cursos de pós-graduação e o controlo e cobrança de inadimplentes. Assim, além das atribuições e competências da função, referenciadas por Grunow et al. (2005), ABMES (2011) e MEC (2010), desempenham tarefas adicionais ao cargo, aspecto que se mostra preocupante, pois nem todos possuem dedicação exclusiva e, a maioria, exerce outra atividade, concomitante à coordenação do curso.

Desta forma, o quadro que se apresenta é de um gestor multifacetado, que precisa administrar muitas informações, conforme evidenciado por Gaglio (2013) e Walter et al. (2012), ou seja, necessita conciliar atividades administrativas e de docência, atividade profissional e outras denominadas 'inerentes à função', o que tende a prejudicar a sua atuação, além de estar em desacordo com as Diretrizes do MEC.

No contexto da gestão dos recursos humanos que the são subordinados, a maioria dos Coordenadores não possui autonomia para administrar o corpo docente do curso. Podem, todavia, apresentar sugestões ao superior imediato, quanto às contratações ou demissões.

Num ambiente em que a atuação dos profissionais está voltada para a geração de informações, as quais são o produto final da atuação dos contadores, concomitante à atuação dos Coordenadores em inúmeras atividades (múltiplas tarefas), um outro indicador mostra-se preocupante: pouco mais de $50 \%$ recebe informações económicas ou financeiras para utilizar na gestão do curso. Além desta particularidade, no conjunto daqueles que as recebem, nem todos concordam que as informações disponibilizadas são suficientes para as finalidades.

Desta forma, além de atuar num ambiente dinâmico, com características muito próprias, a atividade de coordenar precisa ser realizada, não raras vezes sem muitas informações, as quais nem sempre atendem às finalidades específicas ou sequer são utilizadas. Quanto à sua utilização nas decisões, menos de $50 \%$ dos Coordenadores utilizam regularmente as informações recebidas, o mesmo percentual daqueles que as recebem com os atributos da E3 - Revista de Economia, Empresas e Empreendedores na CPLP | Volume 3 | Número 1 
tempestividade e da periodicidade. Esses indicadores ganham maior importância se levarmos em conta que as respostas originam-se em mais de $85 \%$, de IES não públicas. Ou seja, são Coordenadores que atuam em instituições onde os recursos não estão garantidos por orçamento público e dependem das receitas oriundas das mensalidades dos alunos e do oferecimento de cursos de pós-graduação. Esse panorama reforça, ainda mais, a complexidade da atividade e das decisões tomadas, nem sempre sustentadas por informações. Cabe a nós realçar que o questionário aplicado aos respondentes foi construído de raiz, exclusivamente para esta investigação, sendo este, um factor de limitação frente ao estudo. Por outro lado, as informações obtidas e apresentadas permitem a visualização de novas investigações, notadamente quanto aos modelos de gestão praticados nas IES, na relação entre a titulação dos Coordenadores e o uso das informações na gestão. Adicionalmente, os resultados obtidos neste estudo, face à sua abrangência nacional, tendem a ser úteis às IES e aos próprios cursos.

\section{Referências}

Almeida-Santos, P., Domingues, M., Melo, P., \& Cunha, P. (2013). Empreendedorismo na Gestão do Curso de Ciências Contábeis de IES do Norte Brasileiro: Uma contribuição para o Desenvolvimento Regional da Profissão Contábil. Revista de Administração e Negócios da Amazônia, Vol. 5, N.2, maio/ago. 2013.

Associação Brasileira de Mantenedoras do Ensino Superior (2011). Funções do Coordenador de Curso: Como Construir o Coordenador Ideal. Associação Brasileira de Mantenedoras de Ensino Superior. Brasília-DF.

Berg, B., \& Lune, H. (2014). Qualitative Research Methods for the Social Sciences. (8a. Ed.), Edinburgh, Pearson Education Limited.

Beuren, I. (Org.) (2013). Como Elaborar Trabalhos Monográficos em Contabilidade: Teoria e Prática. (3ª Ed.). São Paulo: Atlas.

Bhattacherjee, A. (2012). Social Science Researche: Principles, Methods, and Practices. (2 ${ }^{\mathrm{a}}$. Ed.), Textbooks Collection. Tampa, Florida: USF.

Bonzanini, O. (2012). A Gestão em Um Curso Superior: Revisando as Atribuições e o Papel do Coordenador. Anais do VII Simpósio Nacional de Educação e I Colóquio Internacional de Políticas Educacionais e Formação de Professores. Editora da URI.

Borrel, M., \& León, A. (2010). Procedimiento de Capacitación en Equipos de Trabajo con Enfoque de Competências. Aplicación en un equipo de Alta Dirección. Ingeniería Industrial, Vol. XXXI/No. 3. Recuperado de rii.cujae.edu.cu .

Carvalho, E. (2014). Gestão de Curso Superior: Os Desafios Burocráticos da Prática Profissional do Coordenador de Curso. Revista Gestão Universitária. 
Chinchilla, N., \& Cruz, H. (2011). Diversidad y paradigmas de empresa: un nuevo enfoque. Revista Empresa y Humanismo 2011, Vol. 14, pp. 47-79. Recuperado de http://dialnet.unirioja.es.

Domingues, M., Peleias, I, Walter, S., \& Kroenke, S. (2011). Identificação e Análise do Perfil dos Gestores de Cursos de Ciências Contábeis nos Estados de São Paulo e Santa Catarina. Base - Revista de Administração e Contabilidade da Unisinos. Vol. 8(2), pp. 189-201, abril/junho 2011.

Fayol, Henri. Administração industrial e geral. (9. Ed.). São Paulo: Atlas. 1976.

Ferrari, F., \& Nascimento, K. (2014). Perfil dos Coordenadores de Cursos de Uma Instituição de Ensino Mineira. Revista Eletrônica da Faculdade Metodista Granbery. No. 16, Jan./Junho de 2014. Recuperado de http://re.granbery.edu.br .

Gaglio, G. (2013). Organizational Sense: A Notion for Studying Emerging Organizational Professionalism at Work. Professions \& Professionalism, Vol. 4, No. 1, pp.1-17. Recuperado de www.professionsandprofessionalism.com .

Grunow, A., Sabadin, A., Fassina, P., \& Domingues, M. (2006). Análise do perfil dos gestores do curso de Ciências Contábeis das IES - Instituições de Ensino Superior do Estado de Santa Catariana. Anais do VI Congresso USP de Controladoria e Contabilidade. São Paulo: SP.

Likert, R. (1932). A Technique for the measurement of atitudes. Archives of Psychology, Vol. 22 , n. 140 , pp. 44-53.

Marcon, S. (2011). Atribuições dos cargos de coordenação e subcoordenação de cursos de graduação. Anais do XI Colóquio Internacional Sobre Gestão Universitária na América doSul, Florianópolis-SC. Recuperado de http://repositorio.ufsc.br .

Ministério da Educação. (2010). Instrumento de Avaliação de Cursos de Graduação (Bacharelado e Licenciatura). Sistema Nacional de Avaliação da Educação Superior - SINAES, Setembro de 2010. Brasília: DF.

Muzio, D., Kirkpatrick, I., \& Kipping, M. (2011). Professions, organization and the state: Applying the Sociology of Professions to the case of management consultancy Professions. Current Sociology, 59(6), pp. 805-824. Recuperado de csi.sagepub.com .

Palmeiras, J., \& Szilagyi, J. (2011). Perfil e Competências Necessários para Um Coordenador de Curso na Percepção dos Gestores e Funcionários de Uma IES. Anais do XI Colóquio Internacional Sobre Gestão Universitária na América do Sul. Florianópolis-SC, 7 a 10 de Dezembro de 2011.

Rodrigues, M. (2012). Profissões - Lições e Ensaios. Coimbra: Almedina. 
Santos, A., Domingues, M., \& Ribeiro, M. (2013). Nível de Similaridade das Matrizes Curriculares dos Cursos de Ciências Contábeis das Instituições Paranaenses Listadas no MEC, Ao Currículo Mundial. ReCont - Registro Contábil - UFAL, Maceió. Vol. 4, no. 03, pp.105-127, set./dez. 2013.

Sharrock, G. (2012). University Management: new finance models need better equipped leaders. Higher Education Network. Recuperado de https://www.theguardian.com/highereducation-network.

Sousa, M.; \& Baptista, C. (2011). Como Fazer Investigação, Dissertações, Teses e Relatórios Segundo Bolonha. Lisboa: Pactor.

Tanaka, V., \& Pessoni, L. (2011). A Gestão do Ensino Superior: o Gestor e Seu Papel. Anais do I Seminário Sobre Docência Universitária. Recuperado de www.anais.ueg.br .

Triola, M. (2013). Introdução à Estatística: Atualização da Tecnologia. (11ㄹ. Ed.). Rio de Janeiro: LTC.

Walter, S., Schneider, M., Rocha, D., Domingues, M., \& Tontini, G. (2012). Ações e Perfil Intraempreendedor dos Gestores dos Cursos de Ciências Contábeis da Região Oeste do Paraná. Revista de Educação e Pesquisa em Contabilidade (REPeC), No. 6, Vol. 1, 2012. 